\title{
An Optimization Approach Based on Superstructures for Bioethanol Production from African Palm Kernel Shells
}

\section{Maria J. Sanjuan-Acosta ${ }^{1}$, Karolayn Tobón-Manjarres ${ }^{1}$, Eduardo Sánchez-Tuirán², Karina Angélica Ojeda-Delgado ${ }^{2}$, Ángel Darío González-Delgado ${ }^{*}$ *}

\author{
${ }^{1}$ Nanomaterials and Computer Aided Process Engineering Research Group (NIPAC), Chemical Engineering Department, \\ University of Cartagena, Cartagena, Bolívar, Colombia \\ ${ }^{2}$ Process Design and Biomass Utilization Research Group (IDAB), Chemical Engineering Department, \\ University of Cartagena, Cartagena, Bolívar, Colombia
}

Received: 6 July 2020

Accepted: 15 September 2020

\begin{abstract}
Colombia is a leading country in the production of palm oil, being the fourth in the world and the first in Latin America. However, large quantities of agro-industrial waste are produced from this industry, such as rachis, palm kernel shells, palm kernel cake, oily sludge, and sewage. Through this research, the aim is to find the most efficient route for obtaining bioethanol by taking advantage of a well-known, but not widely used, agro-industrial waste from the production of palm oil: palm kernel shells. This route must be convenient according to technical, economic, social, and environmental criteria of sustainability, for which the synthesis of routes of exploitation of the rachis based on optimization of superstructures will be implemented. In this work, a superstructure empathizing pretreatment stage was constructed with intermittent layers of chemical species required or obtained, and another of technologies for separation or transformation of said chemical species. Organosolv pretreatment (ethanol-acid) and thermochemical pretreatment (pyrolysis) were obtained as results: both routes were evaluated from the break-even point analysis to define which of them to choose as the most promising, giving as a final result the pyrolysis pretreatment.
\end{abstract}

Keywords: agro-industrial waste, bioethanol, palm kernel shell, superstructure

\section{Introduction}

The world's current energy situation and unprecedented population growth have prompted the search for renewable and versatile alternatives to replace the use of fossil fuels with technical, economic and environmentally sustainable energy sources. As a solution, the use of biofuels has been proposed because biofuels are considered $\mathrm{CO}_{2}$ neutral and can be produced from recyclable and abundant materials. This premise has conducted to a large growth in biofuel production systems in recent years [1]. The use of 
agro-industrial waste has attracted attention in recent times for the production of biofuels, especially bioethanol, not only because of the energy potential represented by this type of biomass but also because of the feasibility they generate by not being primary products of the family basket, if not waste with no apparent added value. Lignocellulosic materials are composed mainly of three polymeric constituents: cellulose, hemicelluloses (which together are called holocellulose) and lignin [2].

There are several second-generation bioethanol production projects in the world, and many raw materials have been studied to achieve this objective, from Chlorella vulgaris Cake [3], residues of Agave from the Tequila Process [4], wheat stubble, rice stubble, to palm rachis. Second-generation bioethanol is the product of the alcoholic fermentation of sugars contained in the lignocellulosic material [5]. In general, these sugars are polymeric and must be hydrolyzed to obtain reduced sugars. The efficiency of this hydrolysis depends on the pre-treatment of the raw material. However, with lignin that protects cellulose and hemicellulose from external damage, a pre-treatment step becomes a great challenge to achieve the final yield of the desired bioethanol and greater economic competitiveness of the process [6].

Integrated bioethanol production consists mainly of three stages: i) pre-treatment of dried and ground biomass, ii) enzymatic hydrolysis of solid waste, and iii) fermentation of sugar monomers from cellulose to ethanol. [7]. Taking into account the importance of pre-treatment of biomasses of this type, it is necessary to study the most optimal route(s), technically and economically, for obtaining biofuel, through an innovative method and little-used known as superstructure optimization.

This work attempts to develop a superstructure approach to optimize the production of bioethanol from palm kernel shells with special emphasis in the pretreatment stage. The Organoslv pretreatment and thermochemical pretreatment were analyzed under an economic point of view to select the most promising alternative.

\section{Material and Methods}

The initial phase of this research was the synthesis of the route of exploitation of the palm kernel for the production of ethanol from the design of a superstructure. This design consisted of the search for technological alternatives, based on the bibliographic review, having as fundamental axes the technical and economic factors of each one of the evaluated alternatives. The selection of a lignocellulosic material such as palm kernel, allowed having a wide range of different routes to produce ethanol, introducing 17 technologies in the design of the superstructure, divided between the pretreatment, hydrolysis, fermentation and purification stages.
To establish the pre-treatments to be evaluated in the superstructure, different bibliographic sources were consulted, mainly from the Environmental Protection Agency (EPA) [8], who provided a comparison between all, giving us technical data regarding an important characteristic that our biomass "lignin content presents." (It should be noted that this research is subject to an internal call research project "sustainable use of residues from African palm to obtain biofuels and value-added products under the concept of biorefinery" that suggested the evaluation of four pretreatments (urea, Organosolv, acid and basic).

For the design of the superstructure, standards for process design were used as a guideline model, where chemical pretreatments are selected in order to degrade the lignin present in the biomass and release the components that will proceed to fermentation. Besides, a thermochemical pretreatment in which there is a decomposition of the biomass, forming a compound with the presence of ethanol. These technologies make references to layer 1 .

As recommended Bao, Denny, Douglas, JiménezGutiérrez, and El-Halwagi [9], a "no process" operator was added that allows a species to pass from one layer to another without making any changes. For layer 2, the processes of acid hydrolysis and enzymatic hydrolysis were added since this is how the polysaccharides belonging to the lignocellulosic biomass are hydrolyzed [10]. Additionally, a fermentation and synthesis layer (3) was introduced for the formation of ethanol and to break the azeotrope formed between the water and the alcohol, the last rectification layer was added that allowed obtaining a purity of $95 \%$.

\section{Results and Discussion}

\section{Mathematic Model}

As shown in Fig. 1, the first layer of chemical species is the biomass layer of PKS and is denoted by $\mathrm{C}=1$, while the last layer will be the desired product (Bioethanol) and will be denoted by $\mathrm{C}=$ NP. Therefore, a particular chemical species, $\mathrm{s}$, will be produced in a T-layer of a specific technology, $n$, and can become the raw material of another technology in the $\mathrm{T}+1$-layer.

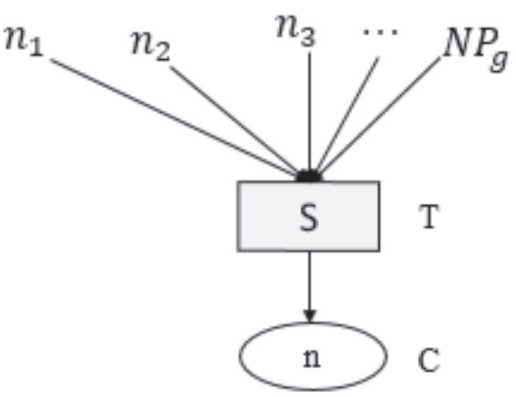

Fig. 1. Superstructure representation 


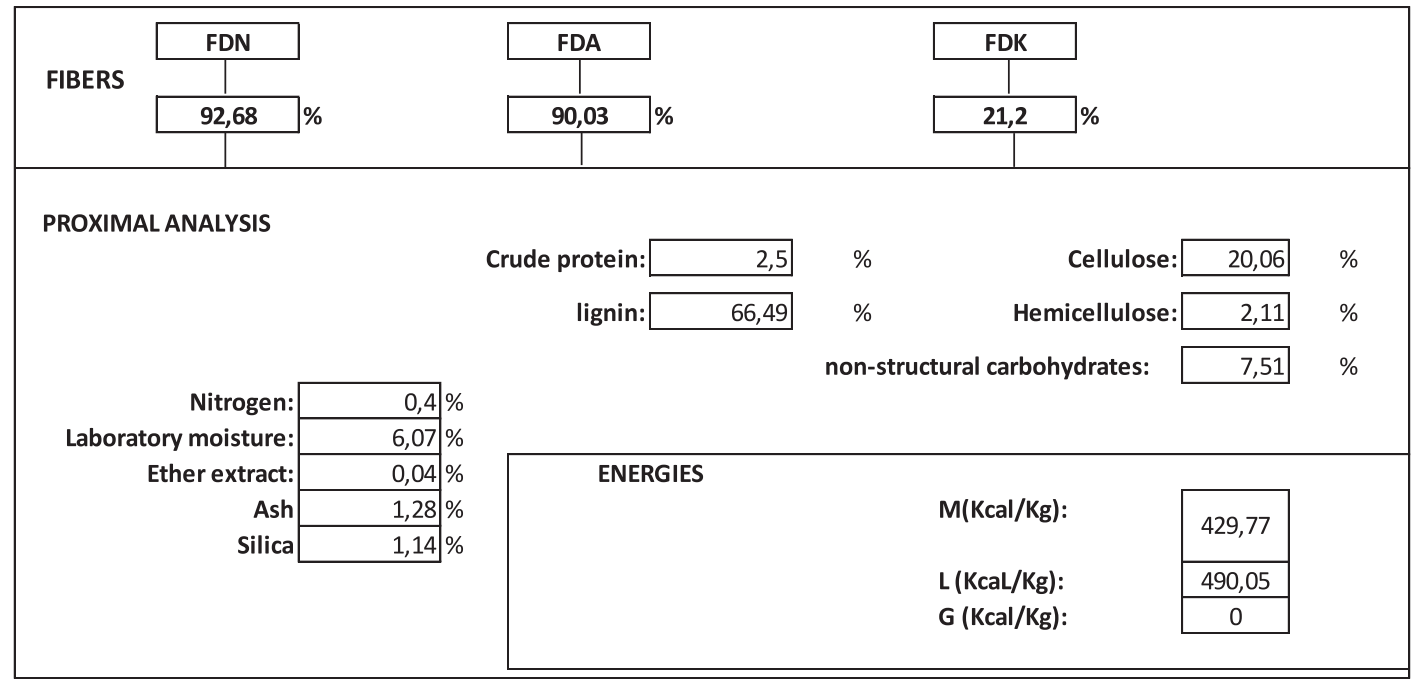

Fig. 2. Characterization of biomass by bromatological analysis.

From the above, we have that the balance of species $\mathrm{s}$ in layer $\mathrm{C}$ is given by:

$$
\begin{gathered}
\mathrm{F}_{\mathrm{n}_{\mathrm{i}}, \mathrm{S}, \mathrm{T}}^{\text {out }}=\sum_{\mathrm{n}_{\mathrm{i}}} \mathrm{F}_{\mathrm{n}_{\mathrm{i}}, \mathrm{s}, \mathrm{T}}^{\mathrm{in}} \\
C=I ; S=c ; T=K ; g=n
\end{gathered}
$$

...where $\mathrm{F}_{\mathrm{n}_{\mathrm{i}}, \mathrm{S}, \mathrm{T}}^{\text {out }}$ and $\mathrm{F}_{\mathrm{n}_{\mathrm{i}}, \mathrm{S}, \mathrm{T}}^{\text {in }}$ are the outflow and inflow, respectively, of the chemical species involved. $\mathrm{F}_{\mathrm{n}_{\mathrm{i}}, \mathrm{s}, \mathrm{T}}^{\text {ow }}$ and $\mathrm{F}_{\mathrm{n}_{\mathrm{i}} \mathrm{s}, \mathrm{T}}^{\mathrm{in}}$ are the outflow and inflow, respectively, of the chemical species involved. In case the chemical species is obtained through a chemical reaction, the mass balance will be:

$$
\mathrm{F}_{\mathrm{s}, \mathrm{T}+1}=\mathrm{F}_{\mathrm{s}, \mathrm{T}}+\sum_{\mathrm{n}_{\mathrm{i}}} \mathrm{r}_{\mathrm{n}_{\mathrm{i}} \mathrm{s}, \mathrm{T}}
$$

\begin{tabular}{|c|c|c|c|c|}
\hline Feed & Technology & $\mathrm{Y}$ & $X$ & Reference \\
\hline \multirow{10}{*}{$P K S$} & Urea & 0.01523 & $56.8 \%$ & {$[11]$} \\
\hline & Methanol-Acid & 0.373 & $26.8 \%$ & [12] \\
\hline & Methanol-basic & 0.7438 & $28 . \%$ & {$[13]$} \\
\hline & Ethanol-acid & 0.24 & $24.7 \%$ & {$[6]$} \\
\hline & Ethanol-basic & 0.7 & $30 \%$ & {$[13]$} \\
\hline & Basic pre-treatment & 0.57 & $60 \%$ & {$[14]$} \\
\hline & Acid pretreatment & 0.85 & $48 \%$ & {$[14]$} \\
\hline & LHW & 0.045 & $30.9 \%$ & {$[15]$} \\
\hline & AFEX & 0.096 & $15 \%$ & {$[16]$} \\
\hline & Pyrolysis & 1 & $85 \%$ & {$[17]$} \\
\hline \multirow{2}{*}{ Hemicellulose } & Acid hydrolysis & 0.5 & $85 \%$ & {$[14]$} \\
\hline & Enzymatic hydrolysis & 0.83 & $90 \%$ & [9] \\
\hline \multirow{2}{*}{ Hemicellulose } & Fermentation & 0.45 & $90 \%$ & {$[9]$} \\
\hline & Dark fermentation & 0.077 & $32 \%$ & {$[18]$} \\
\hline Cellulose & SSF & 0.5 & $90 \%$ & {$[9]-[19]$} \\
\hline \multirow{3}{*}{ Low purity ethanol } & Azeotropic distillation & 0.95 & $99.5 \%$ & {$[20]$} \\
\hline & Extractive distillation & 0.95 & $99.9 \%$ & {$[21]$} \\
\hline & Adsorption with molecular sieves & 0.92 & $95 \%$ & [22] \\
\hline
\end{tabular}

Table 1. Technical data for superstructure optimization. 
Table 2. Palm kernel Shell composition modeled and economic parameters for case study.

\begin{tabular}{|c|c|c|}
\hline Parameters & Units & Values \\
\hline Palm kernel shell composition & & \\
\hline Cellulose & $\%$ & 20.06 \\
\hline Hemicellulose & $\%$ & 2.11 \\
\hline Lignin & $\%$ & 66.49 \\
\hline Extractives & $\%$ & 10.06 \\
\hline Ash & $\%$ & 1.28 \\
\hline Selling price of main product & $\$ / \mathrm{t}$ & 790 \\
\hline Processing capacity & $\mathrm{t} / \mathrm{year}$ & 10000 \\
\hline
\end{tabular}

...where $r_{\mathrm{g}_{\mathrm{i}} \mathrm{c}, \mathrm{k}}$ represents the speed of production/ consumption of the chemical species $\mathrm{c}$, with a positive sign for production and negative for consumption. The flow of each species can be calculated knowing the yield, as follows:

$$
\mathrm{F}_{\mathrm{n}_{\mathrm{i}}, \mathrm{s}, \mathrm{T}}^{\text {out }}=\mathrm{y}_{\mathrm{n}_{\mathrm{i}}, \mathrm{S}, \mathrm{C}} \mathrm{F}_{\mathrm{n}_{\mathrm{i}}, \mathrm{s}, \mathrm{T}}^{\text {in }} \mathrm{X}_{\mathrm{n}_{\mathrm{i}}, \mathrm{T}}
$$

$\mathrm{y}_{\mathrm{n}_{\mathrm{i}}, \mathrm{s}, \mathrm{C}}$ is the performance of the chemical species.
In order to include the economic criterion within the optimization, several particular terms are introduced.

$$
\mathrm{TAC}=\mathrm{AFC}+\mathrm{AOC}
$$

TAC: total annualized costs

AFC: Annualized fixed costs

AOC: Annual operating costs

Considering it stops:

A: Base case (plant for obtaining bioethanol from PKS)

B: Reference cases

For annualized fixed costs

$$
\mathrm{AFC}_{\mathrm{A}}=\frac{\mathrm{AFC}_{\mathrm{B}}}{\mathrm{F}_{\mathrm{B}}^{0,7}} * \mathrm{~F}_{\mathrm{A}}^{0,7}
$$

$$
\mathrm{AFC}_{\mathrm{A}}=\alpha * \mathrm{~F}_{\mathrm{A}}^{0,7} \rightarrow \quad \alpha=\frac{\mathrm{AFC}_{\mathrm{B}}}{\mathrm{F}_{\mathrm{B}}^{0,7}}
$$

For annualized operating costs

$$
A O C_{A}=\frac{A O C_{B}}{F_{B}} * F_{A}
$$

\begin{tabular}{|c|c|c|c|c|c|c|c|}
\hline & Technology & Alfa & $\mathrm{B}(\$ / \mathrm{t})$ & Afc & Aoc & Tac & Adapted from \\
\hline \multirow{10}{*}{ Pre-treatment } & Urea & 112 & 8 & 70730 & 76857 & 147587 & {$[20]$} \\
\hline & Methanol-Basic & 215 & 5 & 135375 & 51931 & 187305 & {$[23]$} \\
\hline & Methanol-Acid & 215 & 5 & 135375 & 51366 & 186741 & {$[23]$} \\
\hline & Ethanol-Basic & 215 & 6 & 135375 & 63851 & 199225 & {$[23]$} \\
\hline & Ethanol-Acid & 215 & 6 & 135375 & 63287 & 198661 & {$[23]$} \\
\hline & Basic pre-treatment & 119 & 21 & 75003 & 208274 & 283277 & {$[6]$} \\
\hline & Acid pre-treatment & 54 & 0 & 34327 & 441 & 34767 & {$[6]$} \\
\hline & Liquid hot water (LHW) & 54 & 0 & 34117 & 438 & 34555 & {$[6]$} \\
\hline & Pyrolysis & 500 & 0 & 315168 & 3094 & 318262 & {$[24]$} \\
\hline & AFEX & 66 & 0 & 41443 & 532 & 41975 & {$[6]$} \\
\hline \multirow{2}{*}{ Hydrolysis } & Acid Hydrolysis & 282 & 0 & 178229 & 2538 & 180767 & {$[25]$} \\
\hline & Enzymatic hydrolysis & 278 & 0 & 175394 & 2497 & 177892 & {$[26]$} \\
\hline \multirow{3}{*}{ Fermentation } & Fermentation & 12 & 35 & 7764 & 353000 & 360764 & [9] \\
\hline & SSF & 142 & 0 & 89544 & 2109 & 91653 & {$[26]$} \\
\hline & Dark fermentation & 2272 & 100 & 1433297 & 1004658 & 2437955 & {$[27]$} \\
\hline \multirow{3}{*}{ Refining } & Azeotropic distillation & 2437 & 16 & 1537893 & 161500 & 1699393 & {$[21]$} \\
\hline & Extractive distillation & 1479 & 10 & 933211 & 98000 & 1031211 & {$[21]$} \\
\hline & Adsorption with molecular sieves & 605 & 5 & 381432 & 45160 & 426591 & {$[21]$} \\
\hline Synthesis & Synthesis & 123 & 42 & 77407 & 415400 & 492807 & [9] \\
\hline
\end{tabular}

$$
\mathrm{AOC}_{\mathrm{A}}=\beta * \mathrm{~F}_{\mathrm{A}} \rightarrow \beta=\frac{\mathrm{AOC}_{\mathrm{B}}}{\mathrm{F}_{\mathrm{B}}}
$$

Table 3. Cost parameters for PKS to ethanol superstructure optimization from an economic point of view. 


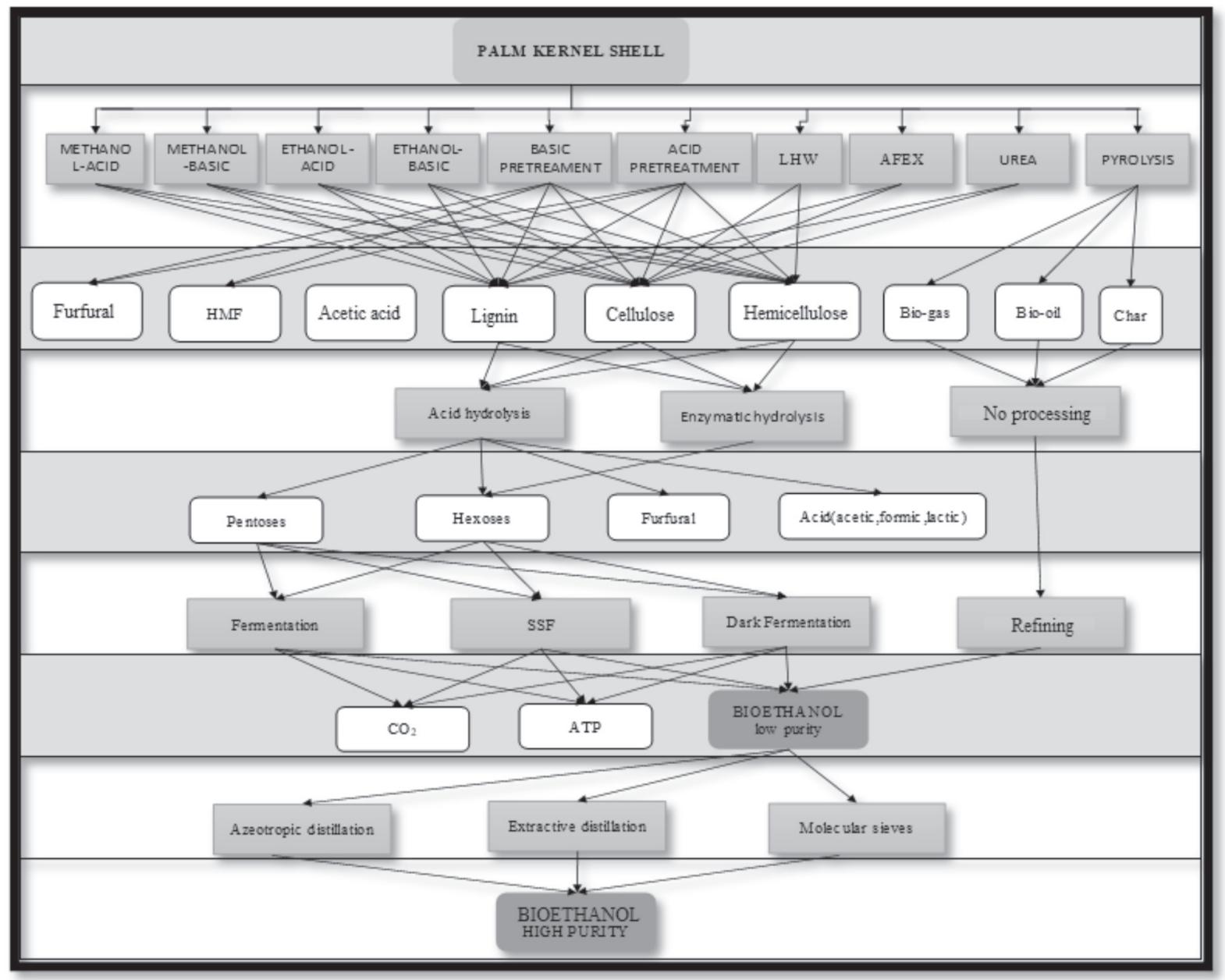

Fig. 3. Superstructure design.

Once the technical and economic criteria have been established, we establish the objective function to program the model in the specialized software, which allowed us to obtain two routes with higher performance at a lower cost, mathematically expressed in the following way:

Max $=\operatorname{cost}_{\text {pro }} * F_{\text {sal }(i)}-\sum \sum T A C_{i, j} * X_{I, J}-\operatorname{Cost}_{P K S} * F_{\text {alim }}$

\section{Case Study}

The case study consisted of evaluating each of the routes established for obtaining bioethanol from PKS; these routes are shown in the superstructure scheme (see Fig. 2). Table 1 shows the yields and conversions referring to each of the technologies evaluated for obtaining bioethanol. The data was selected from different contributions available in the open literature where the product of interest is bioethanol. In many cases, the feed is different, except for organosolv pretreatments, which worked with the PKS as biomass to obtain ethanol, so the data obtained in those investigations were beneficial.
The biomass was analyzed bromatologically providing information related to the composition of cellulose, hemicellulose, and lignin before pretreatment. This information was relevant to perform the optimization taking into account that the data obtained in the different literature work with biomasses whose cellulose, hemicellulose, and lignin contents are different. The data obtained are shown in Table 2.

Table 3 shows the economic data obtained from investigations whose processes were similar to each of the selected routes in our superstructure. The data taken from the literature were the AOC and AFC, which to be adjusted to our case study applying Equations 5 and 8 .

Fig. 3 shows the superstructure design for this case study, where $i$ is all the layers of chemical species; and $\mathrm{k}$ are all the stages of conversion technologies for these chemical species. Based on this superstructure, and taking into account technical and economic data, an optimization code was designed in lingo, to obtain the route that maximizes profits and minimizes costs taking into account the objective function (Equation 9). The best routes for such superstructure are shown in Fig. 4.

For the selection of one of the routes as the most promising for obtaining bioethanol, a break-even point analysis was conducted to evaluate the profitability of 


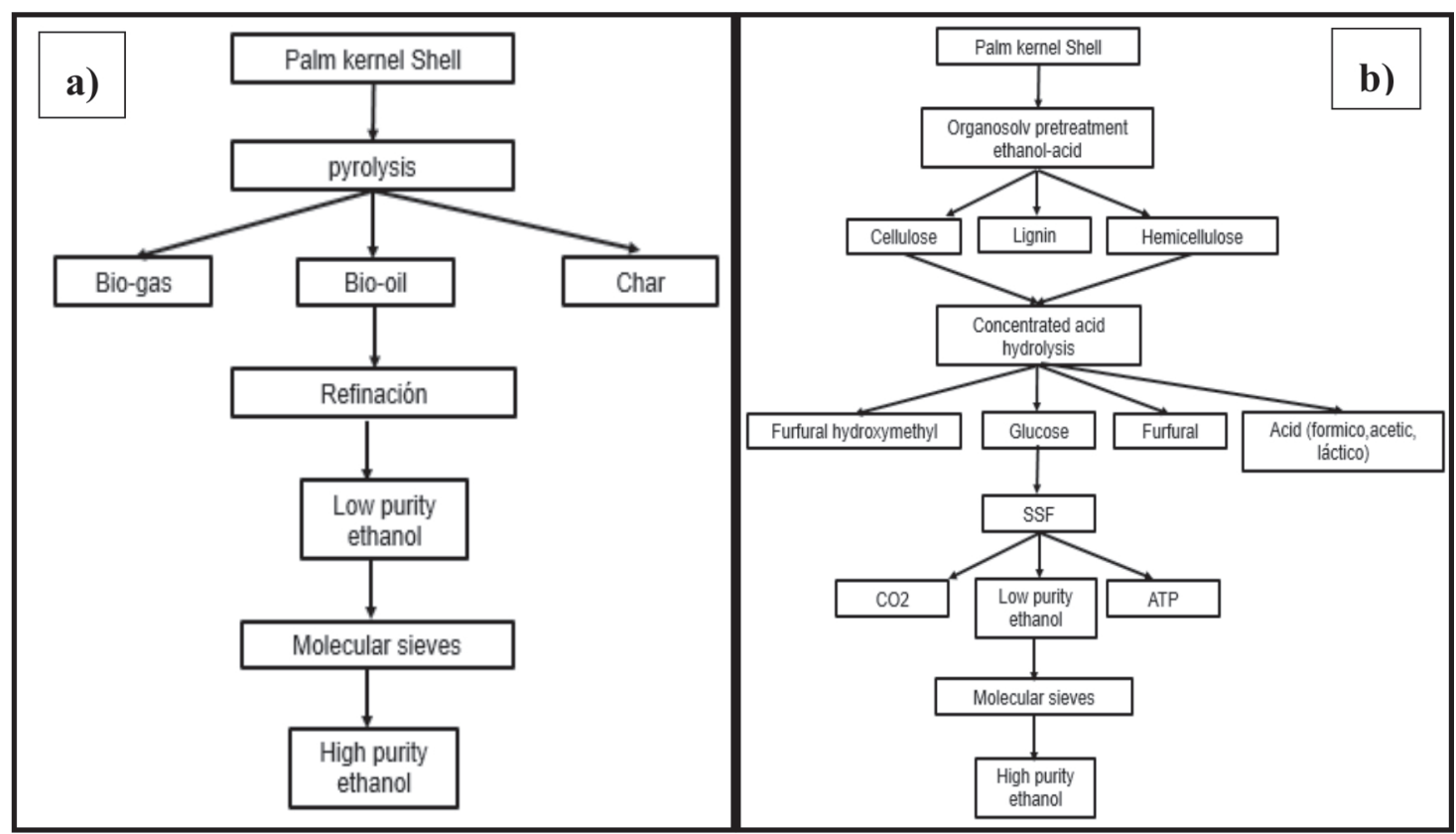

Fig. 4. Optimal pathways for maximum yield of ethanol: a) pyrolysis; and b) acid-ethanol

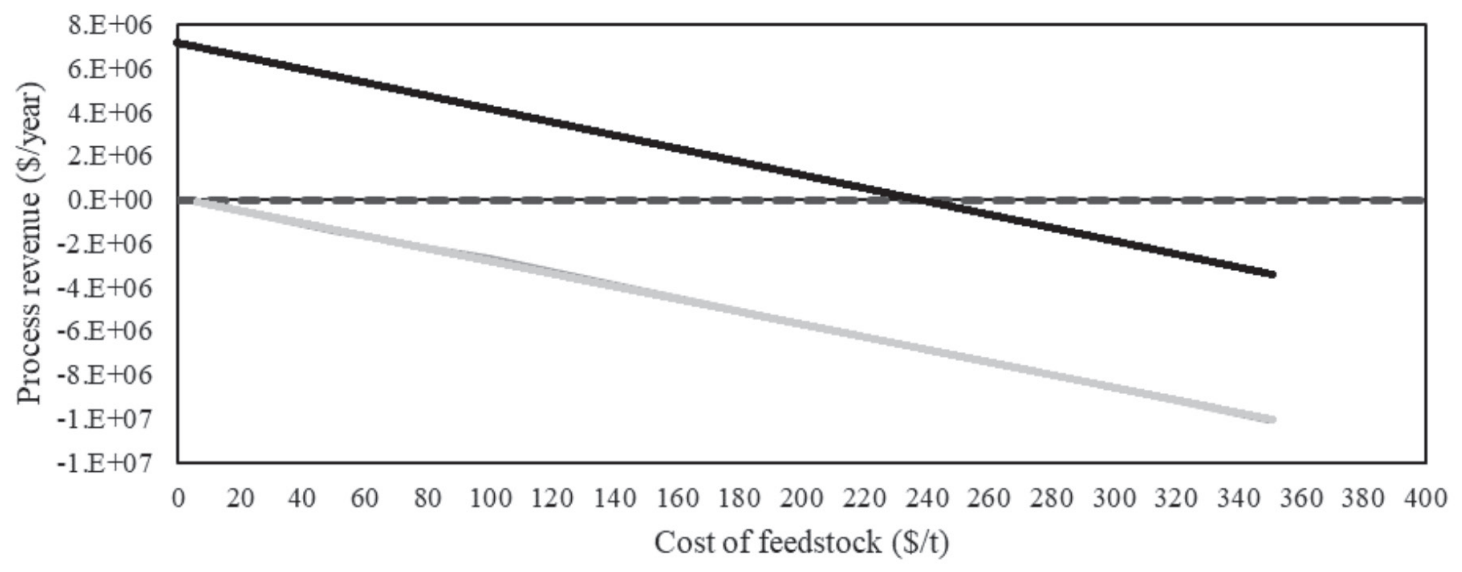

Organosolv (ethanol-acid)

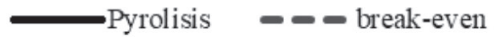

Fig. 5. Break-even sensitivity analysis.

selling bioethanol from each of the routes, taking into account the cost of the raw material and the cost of the profitability generated from it. As shown in Fig. 5, the analysis reported that the best option for bioethanol production is from the pyrolysis process. The breakeven point was useful to identify which of the two alternatives chosen managed to meet assertively with both financial and technical requirements when these technologies want to scale to industrial level leading to the sale of the final product (ethanol). From this, we related the cost of the raw material and the profits, and we obtained that pyrolysis generated a maximum of profitability when having a cost $\$ 0$ of the raw material (PKS) whereas its break-even point, that is to say where the process does not lose, but does not gain either, but can maintain a value of raw material of \$239.

\section{Conclusions}

A methodology for obtaining bioethanol from PKS has been proposed. This methodology is based on integrated approaches that include forward and backward branching, primary product selection, superstructure optimization, comparison of select-ed alternatives. Two promising routes have been selected: Organosolvs Ethanol-acid and pyrolysis.

With the two feasible routes, a sensitivity analysis was conducted where the thermochemical route of pyrolysis was obtained as the most promising route; this may be since stages are saved concerning the conventional pre-treatment routes and also to the high lignin content of the stone, which merits a decomposition of the root of the lignocellulosic material 
present. The maximum of profitability of pyrolysis is reached when having a cost $\$ 0$ of the raw material (PKS) whereas at its break-even point, it can maintain a value of raw material of $\$ 239$.

\section{Acknowledgements}

Authors thank the University of Cartagena, Colombia, for the financing of the research project through the internal project called "Sustainable use of African palm waste to obtain biofuels and value-added products under the concept of biorefinery" legalized in the Commitment Act 006-2017 of Resolution 00476 of 2016.

\section{Conflict of Interest}

The authors declare no conflict of interest.

\section{References}

1. PETROU E.C., PAPPIS C.P. Sustainability of Systems Producing Ethanol, Power, and Lignosulfonates or Lignin from Corn Stover: A Comparative Assessment. ACS Sustainable Chemistry \& Engineering, 2 (11), 2527, 2014.

2. GUARNIZO A., MARTÍNEZ P.N., SÁNCHEZ H. A. Biomass and cellulose pretreatments for saccharification. Scientia et Technica, 15 (42), 284, 2019.

3. MONCADA J., JARAMILLO J.J., HIGUITA J.C., YOUNES C., CARDONA C.A. Production of Bioethanol Using Chlorella vulgaris Cake: A Technoeconomic and Environmental Assessment in the Colombian Context. Industrial \& Engineering Chemistry Research, 52 (47), 16786, 2013.

4. MURILLO-ALVARADO P.E., SANTIBAÑEZAGUILAR J.E., PONCE-ORTEGA J.M., CASTROMONTOYA A.J., SERNA-GONZÁLEZ M., ELHALWAGI M.M. Optimization of the Supply Chain Associated to the Production of Bioethanol from Residues of Agave from the Tequila Process in Mexico. Industrial \& Engineering Chemistry Research, 53 (13), 5524, 2014.

5. HARRIS CORREA R.J. Selection of pretreatments based on the physical-chemical characterization of eucalyptus globulus and populus canadensis residues for the production of bioethanol (thesis). Universidad De Chile, 1-84, 2012.

6. DA SILVA A.R.G., ERRICO M., RONG B.-G. Process alternatives for bioethanol production from Organosolv pretreatment using lignocellulosic biomass. Chemical Engineering Transactions, 57, 1, 2017.

7. KARAPATSIA A., PENLOGLOU G., PAPPAS I., KIPARISSIDES C. Bioethanol Production via the Fermentation of Phalaris aquatica L. Hydrolysate. Chemical Engineering Transactions, 37, 289, 2014.

8. https://www.epa.gov/hwpermitting/method-determiningcompatibility-hazardous-wastes (accessed on May 25, 2020).

9. BAO B., DENNY S., DOUGLAS T., JIMÉNEZGUTIÉRREZ A., EL-HALWAGI M.M. A shortcut method for the preliminary synthesis of process-technology pathways: An optimization approach and application for the conceptual design of integrated biorefineries. Computers and Chemical Engineering, 35 (8), 1374, 2011.

10. PEREZ J. Study of the pretreatment with hot water in liquid phase of wheat straw for its biological conversion to ethanol (thesis). Universidad de Jaén, 1-244, 2008.

11. MALDONADO L., MONTERROSA J. Development of a biorefinery topology from African palm rachis combining methodologies of synthesis, analysis and integration of processes (Thesis). Universidad de Cartagena, 2019.

12. WU C., YUAN H., LIU H., ZHUANG X., ZHAN H., YIN X., HUANG Y., YUAN S. Relevance between chemical structure and pyrolysis behavior of palm kernel shell lignin. Science of The Total Environment, 633, 785, 2018.

13. ORTEGA V., ERLY V. Degradation of oil palm kernel (elaeis guineensis) to obtain fermentable sugars through physical and chemical pre-treatments virgilia (Thesis). Universidad de Cartagena, 2019.

14. PIÑEROS Y. Use of lignocellulosic biomass, some research experiences in Colombia. Universidad Jorge Tadeo Lozano, 2014.

15. YANG H., SHI Z., XU G., QIN Y., DENG J., YANG J. Bioresource Technology Bioethanol production from bamboo with alkali-catalyzed liquid hot water pretreatment. Bioresource Technology, 274, 261, 2019.

16. FONTECHA L.M. Evaluation of the pretreatments with dilute sulfuric acid and AFEX in the lignocellulosic biomass of the giant grass type "Pennisetum Sp" (thesis). Universidad Nacional de Colombia, 1-83, 2011.

17. KUMAR P., BARRETT D.M., DELWICHE M.J., STROEVE P. Methods for pretreatment of lignocellulosic biomass for efficient hydrolysis and biofuel production. Industrial and Engineering Chemistry Research, 48 (8), 3713, 2009.

18. CUELLO-CERA A., MENDOZA-SARMIENTO K., GONZÁLEZ-DELGADO Á.D., PERALTA-RUIZ Y. Agrorefinery synthesis using empty palm fruit bunches as feedstock via superstructure optimization. Chemical Engineering Transactions, 65, 739, 2018.

19. MERAMO SAMIR, OJEDA KARINA S.E. Multifeedstock biorefinery optimization model considering environmental, economic and safety parameters. Conference proceedings, 156, 2016.

20. KUNNAKORN D., RIRKSOMBOON T., SIEMANOND K., AUNGKAVATTANA P., KUANCHERTCHOO N. Techno-economic comparison of energy usage between azeotropic distillation and hybrid system for water e ethanol separation. Renewable Energy, 51, 310, 2013.

21. ZHAO L., LYU X., WANG W., SHAN J., QIU T. Comparison of heterogeneous azeotropic distillation and extractive distillation methods for ternary azeotrope ethanol / toluene / water separation. Computers and Chemical Engineering, 100, 27, 2017.

22. UYAZÁN A., GILL I., RODRÍGUEZ G., CAICEDO L. Ethanol dehydration Ethanol dehydration, 24 (3), 49, 2004.

23. DUARTE Y. Evaluation of the pretreatment and enzymatic hydrolysis stage to obtain ethanol from sugarcane bagasse (Thesis), Universidad Central de las Villas, 1-101, 2008.

24. ZABED H., SAHU J.N., BOYCE A.N., FARUQ G. Fuel ethanol production from lignocellulosic biomass: An overview on feedstocks and technological approaches. Renewable and Sustainable Energy Reviews, 66, 751, 2016. 
25. REALES J.G., CASTAÑO H.I., ZAPATA J.E. Evaluation of Three Methods of Chemical Pretreatment on the Delignification of Cassava Stems. Informacion Tecnologica, 27 (3), 11, 2016.

26. DERMAN E., ABDULLA R., MARBAWI H., SABULLAH M.K. Oil palm empty fruit bunches as a promising feedstock for bioethanol production in Malaysia. Renewable Energy, 129, 285, 2018.

27. CHOI M. KYU, PARK H.C., CHOI H.S. Comprehensive evaluation of various pyrolysis reaction mechanisms for pyrolysis process simulation. Chemical Engineering and Processing - Process Intensification, 130, 19, 2018. 